\title{
O GAECO PARANÁ: duas grandes operações já realizadas e um nome em comum
}

Isabelle Nayara Rompato da Silva ${ }^{1}$ João Vitor Litza Canestraro²

- Enviado em 30/09/2017

- Aprovado em 08/12/2017

\section{INTRODUÇÃO}

É praticamente um fato para todos os brasileiros, que quando se fala de política, automaticamente se fala também de corrupção, esses dois tópicos andam lado a lado, enraizados, desde a época do Brasil colônia. Os mesmos ideais, e pensamentos da elite colonial persistem até hoje nas ações ilícitas daqueles que quando pedem votos, se dizem representantes do povo. (AYER, 2017).

No estado do Paraná isso não é diferente, mesmo parecendo estar mascarada em comparação com outros estados, a corrupção está presente e a cada dia que passa e é possível enxergar isso de maneira mais clara e mais consistente. Um dos principais exemplos é o atual governador do Paraná, Beto Richa, que depois de eleito com ampla maioria dos votos, está perdendo sua popularidade, pois seu nome insiste em aparecer em diversos esquemas de lavagem de dinheiro e improbidade administrativa, mesmo que, ele ainda seja considerado inocente em todas elas. Duas principais e grandes operações realizados pelo GAECO (Grupo de Atuação Especial de Repressão ao Crime Organizado) contra a corrupção e que envolvem o nome do atual governador serão analisadas neste artigo.

\footnotetext{
1 Estudante de Engenharia de Controle e Automação na Universidade Tecnológica Federal do Paraná (UTFPR) isabelle1103@hotmail.com

2 Estudante de Engenharia de Controle e Automação na Universidade Tecnológica Federal do Paraná (UTFPR) joaovitor_1998@hotmail.com.
} 


\section{O GAECO}

O Grupo de Atuação Especial de Repressão ao Crime Organizado, o GAECO, é um grupo de atuação especial criado pela Procuradoria Geral da Justiça em 1995, no estado de São Paulo, porém, foi em 1997 que as funções foram delimitadas com as características mantidas até hoje. A adoção do nome GAECO, e a regionalização, com as áreas de atuação dos respectivos grupos regionais foram estabelecidos por meio da RESOLUÇÃO no 1801, de 19 de setembro de 2007, assinada pelo procurador geral de justiça da época, Milton Riquelme de Macedo ${ }^{3}$. (GAECO, 2011.).

O GAECO tem como função básica o combate a organizações criminosas e se caracteriza pela atuação direta dos promotores na prática de atos de investigação, diretamente ou em conjunto com organismos policiais e outros organismos. O grupo atua de forma singular ou em parceria com o promotor de justiça natural de cada caso, se esse assim o desejar, realizando investigações tanto no corpo de inquéritos policiais em andamento ou que são requisitados e acompanhados pelo grupo, bem como através de Procedimentos Administrativos Criminais instaurados no âmbito do próprio grupo. O GAECO tem como característica uma grande operacionalidade para a ação de atos investigatórios, a atividade é inovadora e difere da atuação criminal comum de cada promotor. (GAECO, 2011).

O GAECO Paraná tem a frente de sua coordenadoria o Procurador Geral de Justiça do Ministério Público do Paraná, Leonir Batisti, e dispõe de oito grupos instalados em diferentes regiões do estado, sendo Curitiba, Londrina, Maringá, Foz do Iguaçu, Cascavel, Guarapuava, Francisco Beltrão e Ponta Grossa. O núcleo regional localizado em Curitiba é responsável por mais 35 cidades além da capital. (GAECO, 2011).

\section{COORDENAÇÃO GAECO PARANÁ}

Leonir Batisti, primeiro, único e atual coordenador do GAECO Paraná é Mestre em Direito pela Universidade Estadual de Londrina, especialista em Metodologia do Ensino Superior pela Unipar - Umuarama, procurador de Justiça do Ministério Público do Paraná e também professor de Direito Processual Penal na Escola da Magistratura - Londrina e Universidade Estadual de

\footnotetext{
3 Foi nomeado como Procurador-Geral de Justiça do Ministério Público do Paraná em 2004 pelo então Governador Roberto Requião. Permaneceu por duas gestões, de 2004 a 2006, e também de 2006 a 2008.
} 
Londrina. Atuava como procurador de Justiça do Ministério Público do Paraná quando foi indicado ao cargo pelo próprio Ministério em abril de 2008. Desde então, segue como coordenador do GAECO e atua de perto em grandes casos solucionados pelo grupo. (MINISTÉRIO, 2017)

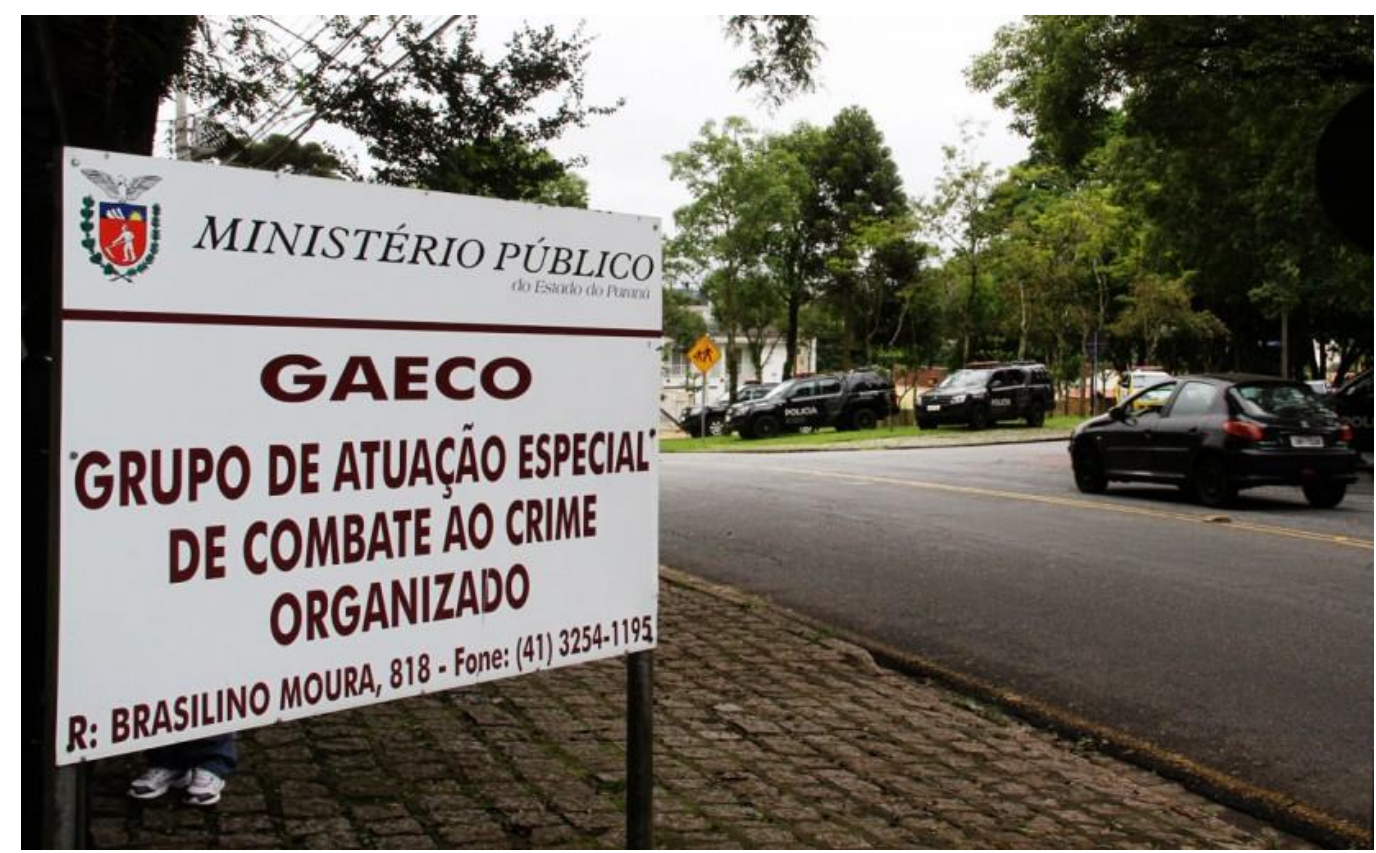

Fonte: http://www.tribunapr.com.br./ Acesso em: 10/11/2017

\section{OPERAÇÃO QUADRO NEGRO}

Uma das maiores operações já realizadas pelo GAECO, a operação "Quadro Negro" descobriu a existência de uma organização criminosa constituída por empresários e funcionários públicos que desviavam recursos destinados a obras em escolas. Inúmeros servidores atestavam falsamente que as fases de diversos serviços estavam adiantadas, enquanto algumas não haviam sequer saído do papel, e com isso a empresa responsável pelas obras, a "Valor Construtora", recebia valores indevidos do Estado. O dono da construtora, Eduardo Lopes de Souza, seus familiares e outras pessoas ligadas a ela, além de terem pago propina a um servidor, praticaram também lavagem de dinheiro, adquirindo veículos de alto valor, móveis e imóveis em nome de terceiros e também repassavam dinheiro para contas de diferentes pessoas com o objetivo de tentar camuflar os valores desviados. A denúncia indica também que o empresário, dono da 
construtora, falsificou documentos (declarando ter concluído obras) para participar de licitação em outro órgão público. A organização se estendeu de 2013 até pelo menos julho de 2015, causando aos cofres públicos um prejuízo estimado de $\mathrm{R} \$ 18$ milhões de reais. As investigações começaram inicialmente pelo Núcleo de Repressão a Crimes Econômicos (NURCE) da Polícia Civil e foram complementadas pelo GAECO, que em Dezembro de 2016 cumpriu diversos mandados de prisão e de busca e apreensão. (MINISTÉRIO, 2016; MINISTÉRIO 2013).

\begin{tabular}{|c|c|}
\hline \multicolumn{2}{|c|}{$\begin{array}{l}\text { Veja quais são as obras previstas nos contratos } \\
\text { firmados entre a empresa Valor Construtora e } \\
\text { Serviços Ambientais e a Secretaria de Estado da } \\
\text { Educação (Seed) que são alvos da Polícia Civil por } \\
\text { irregularidades nos pagamentos: }\end{array}$} \\
\hline \multicolumn{2}{|c|}{$\begin{array}{l}\text { Cornélio } \\
\text { Procópio }\end{array}$} \\
\hline \multicolumn{2}{|r|}{$\begin{array}{c}\text { Joaguim } \\
\text { Távora }\end{array}$} \\
\hline \multirow{2}{*}{\multicolumn{2}{|c|}{$\begin{array}{l}\text { Sta. Terezinha } \\
\text { do ltaipu }\end{array}$}} \\
\hline & \\
\hline Coronel Vivida & Rio Negro \\
\hline \multicolumn{2}{|l|}{ CONSTRUÇÃO } \\
\hline Colégio & município \\
\hline Colégio Arcangelo Nandi & Sta. Terezinha do Itaipu \\
\hline Colégio Willian Madi & Cornélio Procópio \\
\hline Colégio Jardim Paulista & Campina Grande do Sul \\
\hline Colégio Ribeirăo Grande & Campina Grande do Sul \\
\hline Colégio Tancredo Neves & Coronel Vivida \\
\hline \multicolumn{2}{|l|}{ REFORMA } \\
\hline Colégio Professor Lysimaco Ferreira Costa & Rio Negro \\
\hline Colégio Amâncio Moro & Curitiba \\
\hline Colégio Doracy Cazarino & Curitiba \\
\hline Colégio Estadual Campo Distrital de Joa & Joaquim Távora \\
\hline Colégio Professora Linda Salamuni Bacila & Ponta Grossa \\
\hline
\end{tabular}

Fonte: Polícia Civil./ Acesso em: 22/11/2017.

Um dos mandados de prisão incluía Maurício Fanini, ex-diretor da Seed (Secretaria de Educação do Paraná) e também ex-diretor da Superintendência de Estado da Educação (Sude). Fanini é acusado de fazer parte do esquema e de ordenar que fiscais atestassem a evolução da 
obra sem de fato comparecer ao local, o que, a partir destes documentos, possibilitou a liberação de pagamentos à construtora independente da obra estar em andamento ou não. (JUSTI, 2017).

Uma denúncia feita ao Ministério Público em Novembro de 2014 aponta que Fanini recebia cerca de $2 \%$ do valor de cada fatura paga para a empresa Valor Construtora, de Eduardo Lopes de Souza, que era encarregada das supostas obras. Com o intuito de tentar garantir a possibilidade de ressarcir o erário, em caso da condenação do acusado, a 9a vara criminal de Curitiba ordenou em Setembro de 2017, o sequestro de um imóvel de Fanini no valor de $\mathrm{R} \$ 1$ milhão de reais, localizado no bairro Cabral em Curitiba. O ex-diretor da Superintendencia de Estado da Educação (Sude) tentou já com a operação quadro negro em andamento, dissimular a posse do imóvel transferindo-a aos dois filhos. O sequestro de bens foi requerido pelo GAECO, que é responsável pelas investigações. (ANNIBAL, 2017; MINISTÉRIO, 2017).

O principal delator da operação Quadro Negro, o empresário Eduardo Lopes de Souza, dono da construtora Valor, mencionou Fanini diversas vezes. Segundo o construtor, Fanini cobrou diretamente o pagamento de propina e chegou a receber o dinheiro em uma mochila e em caixas de vinho, no gabinete em que ocupava, na Sude. Além disso, o ex-diretor teria assegurado que os recursos desviados abasteceriam a campanha do governador Beto Richa. Segundo o delator, Fanini esperava levantar $\mathrm{R} \$ 32$ milhões por meio do esquema, e que parte do dinheiro serviria para cobrir gastos da campanha do atual governador, Beto Richa, que até o momento nega todas essas acusações. (ANNIBAL, 2017).

\section{QUEM É MAURICIO FANINI}

Maurício Jandoi Fanini Antonio nasceu no ano de 1965, no mesmo ano de nascimento do governador e amigo, Beto Richa. Ambos cursaram Engenharia Civil na Pontifícia Universidade Católica do Paraná (PUC) e se formaram juntos, na década de 80 . Beto Richa foi eleito viceprefeito de Curitiba no ano de 2001, e logo em seguida Fanini foi nomeado diretor de Pavimentação, já que o vice-prefeito assumiu também a pasta de Obras Públicas da administração da capital. (SCORTECCI, 2017).

Com a vitória de Beto Richa nas eleições para governador em 2010, Maurício assumiu outro cargo de confiança, se tornou diretor de Engenharia, Projetos e Orçamentos da 
Superintendência de Desenvolvimento Educacional (Sude), "braço" da Secretaria de Educação (Seed). Na Sude, Fanini ficou durante todo o primeiro mandato do governador, entre 2011 e 2014 e nesse período ele também foi presenteado com uma cadeira no Conselho de Administração da Sanepar (Companhia de Saneamento do Paraná). (SCORTECCI, 2017).

Logo em 2013, Maurício Fanini recebeu uma ação civil pública por atos de improbidade administrativa. Ele e outras 22 pessoas - todos negam qualquer ilegalidade - teriam direcionado uma parcela de processos licitatórios para uma empresa do ramo de construção civil. Esse foi apenas o início de supostas irregularidades cometidas pelo então diretor de pavimentação. Também em 2013, Fanini foi chamado pela Polícia Federal para prestar esclarecimentos sobre fatos apurados na Operação Sinapse - uma investigação sobre desvios de recursos públicos do Ministério da Educação, a partir de convênios feitos entre o Instituto Federal do Paraná (IFPR) e duas Organizações da Sociedade Civil de Interesse Público (Oscips), com sedes em Curitiba. Para a polícia, as Oscips simularam contratos com algumas empresas e apresentaram notas fiscais por serviços não prestados, com o intuito de justificar o dinheiro recebido pelos convênios com o IFPR. Entre as empresas, estava a B.M.A Linguagem e Comunicação, cujo o dono é Marcelo Fanini, e o nome da empresa corresponde as iniciais da esposa de Fanini, a fonoaudióloga Betina Moreschi Antonio, que por sua vez, tem parte societária. Na época, os dois disseram à polícia que os serviços foram de fato prestados, e não chegaram a ser indiciados. Contudo, o nome da B.M.A Linguagem e Comunicação voltou a aparecer na Operação Quadro Negro, quando o casal foi acusado de usar a empresa para lavar dinheiro. (SCORTECCI, 2017; GLOBO, 2017). No segundo mandato de Beto Richa, outra missão foi dada a Fanini: a de recriar a Fundepar, autarquia que ficaria responsável por toda a parte administrativa da pasta de Educação, como contrato de obras, de merenda e de transporte. Seu cargo foi interrompido pela Operação Quadro Negro, já em meados de 2015, quando Fanini chegou a ser preso, mas logo obteve liberdade. Foi quando tudo pareceu começar a desmoronar para o "longamanus" do governador. No final do mesmo ano, Fanini foi denunciado pelo Ministério Público do Paraná, apontado como peça central no desvio de dinheiro de contratos firmados entre a Seed e a empresa Valor Construtora. Foi o início da Operação "Quadro Negro", que segue com investigações até o momento atual. (SCORTECCI, 2017; GLOBO, 2017). 


\section{OPERAÇÃO PUBLICANO}

A Operação "Publicano", deflagrada em março de 2015, tem como objetivo desarticular uma organização criminosa formada por auditores fiscais da Receita Estadual do Paraná, contadores e empresários. Além de corrupção, a operação combate também crimes de falsidade de documentos e lavagem de dinheiro. (SANTOS, 2017).

O nome da operação se dá de uma origem bíblica onde os publicanos eram os responsáveis pela arrecadação de impostos e tributos no Império Romano. Com o passar do tempo, o termo publicano passou a designar cobradores ilegais que, usando o poder a eles conferido, enriqueciam de forma ilícita. (OSTI, 2017). As investigações começaram nove meses antes, em junho de 2014 e revelaram, segundo o Ministério Público, que um grupo de auditores fiscais cobrava propina de empresários para não aplicarem ou perdoarem multas por sonegação. Pelo menos 13 empresas teriam participado do esquema ou sido abordadas pelo grupo. Cerca de $\mathrm{R} \$ \mathbf{5 0 0}$ milhões em dívidas de empresas com o fisco estadual teriam passado pelo crivo desses auditores. (SAVIANI, 2015).

O MP denunciou o grupo por corrupção passiva, formação de organização criminosa, falso testemunho, falsidade ideológica entre outros crimes.

Segundo as investigações do Gaeco (Grupo de Atuação Especial de Combate ao Crime Organizado), os auditores fiscais da Receita Estadual do Paraná começaram a praticar extorsão em 1984. A investigação é baseada em dezenas de relatos de auditores fiscais e empresários que firmaram acordos de delação premiada. (FOLHA, REIS, 2015).

Os investigadores também tiveram acesso a anotações, escutas telefônicas, documentos de empresas que teriam sido alterados ilegalmente por auditores, movimentações suspeitas em contas bancárias e processos não concluídos abertos na Receita. (FOLHA, REIS, 2015).

O principal delator do caso, o auditor Luiz Antônio de Souza ${ }^{4}$, disse que parte da propina abasteceu a campanha de Beto Richa no ano de 2014. Segundo ele, a IGF (Inspetoria-Geral de Fiscalização) repassava valores diretamente para Luiz Abi Antoun, primo do governador, preso em decorrência da operação. Ao todo, teriam sido R\$ 4,3 milhões. (GAZETA, 2017).

A denúncia da segunda fase da Operação Publicano, deflagrada pelo Grupo de Atuação

\footnotetext{
4 Luiz Antônio de Souza trabalhava na Receita Estadual do Paraná desde julho de 1985. O auditor fiscal foi preso em janeiro de 2015 quando foi flagrado em um motel de Londrina com uma adolescente de 15 anos. Desde então, tem colaborado com as investigações para desvendar esquemas de corrupção.
} 
Especial e Combate ao Crime Organizado (GAECO) tem uma extensa lista de denunciados, e pode ser observada a seguir: (BONDE, 2015).

Auditores fiscais:

Ademir de Andrade

Amadeu Serapião

Amado Batista Luiz

Ana Paula Pelizari Marques Lima

Antônio Aparecido de Hercules

Antonio Carlos Lovato

Ataliba José de Souza Filho

Benedito Maciel Goes

Carlos Eduardo Reginato

Claudine de Oliveira

Clovis Agenor Rogge

Divaldo de Andrade

Djalma Correa

Douglas Vitorio da Silva

Ederson Luiz Bonatto

Edilson Edimar Ferreira

Eurico Rosa de Almeida

Gilberto Della Coletta

Gilberto Favato

HelioHisashiObara

Jaime Kiochi Nakano

Jane Elen Reis Cotta

João Marcos de Souza

José Antônio Correa Neto

José Aparecido Camargo

José Aparecido Valencio da Silva

José Henrique Hoffmann

José Luiz Favoreto Pereira

Laércio Rossi

Lidio Franco Samways Junior

Lindolfo Traldi

Luís Claudio Depes Eiras

Luiz AntonioBelarmino

Luiz Antônio de Souza

Luiz Antônio Marqueze

Marcio de Albuquerque Lima

Mario Aparecido Sanzovo

Marco Antonio Bueno

Marcos Colombo

Marcos Luís Ferreira Arrabaça 
Maurilio Nicolau

Miguel Arcanjo Dias

Milton Antonio de Oliveira Digiacomo

Nelson Mandelli Junior

Paulo Sergio Chagas Terra

Ranulfo Dagmar Mendes

Ricardo de Freitas

Roberto Carlos Ricardo

Roberto KenitiOyama

Ronivaldo Costa Zani

Rosângela de Souza Semprebom

Samir Malouf Ibrahim

Sérgio Paulo de Souza Quaresma

Silvano Aparecido Bonilha

Wagner Raimundo Chrispim

Wilson Sergio Boni

\section{Advogados:}

Fabricio Resende Camargo

Miguel Sali El Kadri Teixeira

\section{Contadores:}

Hederson Flávio Bueno

Jorge Dias Paiva

Jose Constantino

Luiz Sergio Rufato

Maria Perpétua de Souza Rodrigues

Paulo Kazuo Yamamoto

Paulo de Tarso Goulart

Tarcisio de Castro Vieira

Valdir Liuti

YukioOgata

\section{Empresários:}

Luiz Abi Antoun

Adelino Favoreto Junior

Adriana Fernandes de Andrade Barrueco

Amado Gois

Antonio Aparecido Trombini

Anunciata Luiza MenegonRomera

Bruna Sanches Muniz

Carlos Luiz Lobo

CibelleHarumiSugayama

Claudinei Delbianco 
Claudinei Martins Vilha

Claudio Cezar Camacho

Danielly Saderi Garcia

Deborah Monique Fernandez

Diogenys Marcelo Carandina

Edson Leandro Pereira

Edivaldo Gomes de Souza

Edilson Irineu Sanches Calvo

ElisonCattaneo Estrada

Fábio Fernando Trevizan

Fabio YoshimuraAjita

FelisbauNegrisoli

Henrique Yoshio Sato

Humberto Amaral

Ivan Cleber Martins e Oliveira

João Roberto de Souza

José Eliseu da Silva Pereira

José Marcos Calsavara

José Maria Fernandes

José Olive Martinez

José Roberto Pontalti

Julio Cesar de Morais Camargo

Leonildo Fritzen

Leonildo Marques de Lima

Luiz Antônio Garcia

Luiz Pontes de Oliveira Filho

Marcelo de Castro Luz

Márcio José Mendes

Marcos Araújo Moro

Marcos Cesar Artacho

Marcus Aurelius de Andrade Pezotti

Maria Luiza Romera Milani

Maria Teresa Sanches Calvo

Mario da Fonte Inácio

Maurício Pedro Sanches Muniz

Maurício Gonçalves

Milton Lenharo

NezioBorri

Osmar Milani

Paulo Pasquini

Paulo Roberto Enelli

Robertson Caetano Pinto

Roselaine LuppiSavariego

Sergio Fujiwara

Valdecir Dario 
Vinicius Duque Peinado

William Rodrigues

Entre os denunciados e presos está Márcio Albuquerque Lima $^{5}$, ex-inspetor geral de fiscalização da Receita Estadual, que é apontado pelo MPE como líder da quadrilha. (OYA, 2016).

Outro mandado de prisão é contra o empresário Luiz Abi Antoun, primo em sétimo grau do governador Beto Richa (PSDB), que já havia sido acusado de envolvimento em um esquema de fraude em licitações para um serviço de manutenção de veículos do Estado. Luiz Abi Antoun vinha sendo investigado pelo Gaeco por uma série de crimes, incluindo fraude em licitações. Segundo os promotores, o empresário é dono de uma oficina usada para fraudar uma concorrência pública do governo estadual. A empresa Providence, que está em nome de um "laranja", foi contratada em dezembro do ano de 2015 e teria recebido cerca de um milhão e meio de reais para fazer a manutenção de veículos oficiais durante um semestre. (BAND, 2015; MARTINEZ, 2016).

\section{O GOVERNADOR, NOME QUE SE REPETE}

Em ambas as operações analisadas, é possível observar um nome em comum: Beto Richa, o atual governador do Paraná, que exerce seu segundo mandato e foi eleito sem a necessidade de um segundo turno. Beto Richa, que já venceu eleições anteriores com grande índice de aprovação, tem sua popularidade decaindo gradativamente nos últimos anos de governo, devido a diversos escândalos envolvendo seu nome, embora não haja de fato, provas contra o governador. Entre dezembro de 2014 e fevereiro de 2015 , a popularidade do tucano caiu de $64 \%$ de aprovação a $76 \%$ de rejeição. (RUSCHEL, 2015).

Além da operação "Quadro Negro" e da operação "Publicano", em que o governador é citado, é importante também relembrar o episódio que ficou conhecido como "29 de abril", quando a polícia, sob o "aval" do governador, entrou em um confronto violento com professores e servidores que faziam uma manifestação pacífica em frente à Assembléia Legislativa do Paraná. Diversas pessoas ficaram feridas em 29 de abril de 2015, e após a repercussão do caso em diversos

\footnotetext{
${ }^{5}$ Márcio Albuquerque de Lima é ex inspetor geral de fiscalização da Receita Estadual, amigo e co-piloto do governador Beto Richa nas corridas de 500 milhas de Londrina. Márcio foi condenado a 97 anos de prisão por corrupção ativa, passiva e organização criminosa.
} 
canais virtuais, Beto Richa ganhou o apelido de "ditador do Paraná" e rendeu ao governador e ao Secretário de Segurança da época, Fernando Francischini, um processo que pedia que ambos, e os policiais militares que comandavam a operação fossem responsabilizados por improbidade administrativa. Richa e Francischini foram considerados inocentes. (ANNIBAL; RIBEIRO, 2017). No ano seguinte, inúmeras escolas foram ocupadas por estudantes que manifestavam contra a Medida Provisória $746^{6}$, que fragmenta o ensino médio, e também contra a PEC $241^{7}$, que engessa investimentos em educação e saúde. O estado do Paraná concentrava o maior número de escolas ocupadas, com um total de mais de 600. Uma das grandes reclamações entre os estudantes foi de que não houve nenhum tipo de diálogo entre o movimento estudantil e o governador Beto Richa, o governador entrou com pedido de reintegração de posse a cada escola ocupada, e em alguns casos, isso ocorreu de forma violenta. (OLIVEIRA, 2016).

Coincidentemente, as duas operações decorrentes dos dois maiores escândalos de corrupção do segundo mandato de Beto Richa, a "Quadro Negro" e a "Publicano" estão paralisadas até os ministros do Superior Tribunal de Justiça (STJ), em Brasília, decidirem o destino das investigações já que o governador do Paraná foi citado por réus no primeiro grau da Justiça Estadual.

Segundo os membros do Gaeco, assim que o nome de Beto Richa surgiu durante as investigações, as peças que mencionavam o tucano foram encaminhadas à ProcuradoriaGeral da República (PGR), em Brasília, que é quem tem competência para pedir ou não a abertura de um inquérito no STJ. O procedimento foi adotado nas duas operações do Gaeco. Em função disso, na Operação "Publicano", Beto Richa inclusive já é formalmente investigado no STJ, através do inquérito 1.093. Na Operação "Quadro Negro", em função das delações, o tucano ainda pode se tornar alvo de um inquérito. (SCORTECCI,Catarina, 2017).

\section{VIDA E TRAJETÓRIA POLÍTICA}

Carlos Alberto Richa é neto de comerciantes libaneses, filho de José Richa ${ }^{8}$ - ex governador do Paraná, que teve sua carreira iniciada em 1962 quando se elegeu deputado federal e filiou-se ao "Movimento Democrático Brasileiro" (MDB) sendo também um de seus fundadores. Beto

\footnotetext{
${ }^{6}$ Informações em: https://www.congressonacional.leg.br/materias/medidas-provisorias/-/mpv/126992

${ }^{7}$ Congela as despesas do Governo Federal, com cifras corrigidas pela infração, por até 20 anos. (EL PAÍs, 2016).

8 José Richa destacou-se na luta pela democracia, realizando em Curitiba, em 1984, o primeiro comício do país pelas “Diretas já".(TRIBUNA, 2008).
} 
Richa passou a sua infância no norte do Paraná, onde nasceu, em 1965. Mudou-se para Curitiba posteriormente, onde freqüentou o ensino médio e também se graduou, em Engenharia Civil pela Universidade Católica do Paraná (PUC-PR), e ingressou na carreira política aos 29 anos, inspirado pela trajetória do pai. (WILLE, 2016).

Sua primeira disputa eleitoral foi como candidato a vereador em Curitiba, porém, Beto Richa obteve apenas 1.882 votos, insuficiente para a eleição. (GAZETA, 2014).

Dois anos depois, em 1994, foi eleito deputado estadual com 22 mil votos e criou leis importantes, como a indenização a famílias de ex-presos políticos e a obrigatoriedade de bancos instalarem câmeras nos caixas eletrônicos. Conhecida como "Lei Beto Richa", determinou o pagamento de indenização, pelo governo estadual, aos ex-presos políticos que sofreram repressão durante a ditadura militar no Brasil. A lei tornou-se modelo e foi instituída em outros estados brasileiros e reconhecida pela Anistia Internacional como de relevância política que contribuiu para o avanço institucional do Estado e do País. (TRIBUNA, 2008)

Quatro anos mais tarde foi reeleito, mas desta vez, com o dobro de votos. (TRIBUNA, 2008; GAZETA, 2014).

No ano de 2000, Beto foi escolhido para ser o candidato a vice-prefeito na chapa de Cassio Taniguchi. Com a eleição, Richa assumiu a Secretaria Municipal de Obras Públicas no ano seguinte. (GAZETA, 2014).

2002 ele se candidatou pela primeira vez ao governo do estado. Obteve 888.796 votos e ficou na terceira posição, voltou então, a assumir a vice prefeitura de Curitiba. Dois anos depois, obteve êxito e foi eleito prefeito de Curitiba, com $54,78 \%$ do total de votos, e cria a tarifa de ônibus a $\mathrm{R} \$ 1,00$ aos domingos. (GAZETA, 2014).

Foi reeleito prefeito de Curitiba em 2008, ainda no primeiro turno, com recorde de votos, obteve 77,27\% dos votos válidos. Em 30 de março de 2010, renunciou a prefeitura da capital com o intuito de concorrer ao governo do estado, e mais uma vez obteve êxito ao ser eleito com mais de 3 milhões de votos. Fato que se repetiu 4 anos depois, quando Richa foi reeleito governador com 3,3 milhões de votos. (TRIBUNA, 2008; GAZETA, 2014).

Logo que assumiu o governo do estado em 2010, ao anunciar os nomes de sua nova equipe, Richa indicou seu irmão José Pepe Richa Filho como secretário de Estado e Infraestrutura e Logística, e também nomeou sua esposa Fernanda Bernardi Vieira Richa, com quem é casado 
desde 1985, como Secretária de Estado da Família e Desenvolvimento Social do Paraná, cargo que ela ocupa até o momento. Anteriormente, de 2005 a 2010, Fernanda presidiu a Fundação de Ação Social (FAS) em Curitiba. (DESENVOLVIMENTO; MOSER, 2010).

\section{CONSIDERAÇÕES FINAIS}

É perceptível que, nos últimos anos, inúmeros escândalos de corrupção foram desvendados, e alguns até solucionados. Seja no plenário, no senado ou na câmara de deputados, todo e qualquer esquema de corrupção dispõe de crimes gravíssimos cometidos de abuso de poder público. Os recorrentes noticiários de escândalos de corrupção ativa e passiva através de oferecimento e recebimento de propinas, desvios de dinheiro e licitações fraudulentas, envolvendo principalmente governantes, servidores públicos e empresas, têm despertado na população um alerta sobre a importância do combate à corrupção. (SAMPAIO, 2016). Com o decorrer do tempo, os crescentes episódios de corrupção e o consequente enfraquecimento dos mecanismos coibidores e fiscalizatórios, aumentam os casos de impunidade, gerando desconfiança na população. No Brasil, segundo a Organização das Nações Unidas (ONU), estimase que são desviados por ano, aproximadamente, $\mathrm{R} \$ \mathbf{2 0 0}$ bilhões (duzentos bilhões de reais). Portanto, não é difícil perceber que o estado em que o país se encontra no momento atual não é apenas reflexo de ações recentes, mas de um grande histórico de crimes contra a população. (SAMPAIO, 2016). Diante isso, é importante também que chegue ao conhecimento da população os programas e atividades realizadas pelos órgãos públicos voltados ao combate à corrupção. Como as duas Operações realizadas pelo Gaeco analisadas anteriormente, a "Quadro Negro" e a "Publicano". É necessário que os cidadãos saibam e apoiem essas ações. Em destaque, nota-se o trabalho do Ministério Público brasileiro, em todos os seus ramos, no que se refere à repressão e prevenção da corrupção, bem como na conscientização da população. (SAMPAIO, 2016).

\footnotetext{
MOBILIZAÇÃO SOCIAL E CONTROLE DA CORRUPÇÃO: Somente os cidadãos e os grupos organizados podem impulsionar a mudança necessária para a criação e o fortalecimento de uma nova cultura de controle político e social. Com transferência, acesso às informações e uma estrutura técnica para correta interpretação dos acontecimentos, podemos denunciar práticas corruptas escamoteadas e cobrar uma apuração. A luta contra o fenômeno da corrupção exige uma mobilização nacional destinada a pressionar nossos representantes políticos para que passem a agir com mais transparência e
} 
visibilidade. Também cabe individualmente a cada cidadão denunciar às autoridades competentes (Ministério Público, por exemplo) os subornos e os ilícitos que permitem a continuidade do mercado de atividades ilegais institucionalizadas na máquina pública. Todavia, vale a advertência de Susan Rose-Ackerman, para fazer que as reclamações (denúncias) tenham algum valor, as investigações (processos) devem ser imparciais, rápidas e eficazes. (GUIZZO, 2016).

\section{REFERÊNCIAS}

ANIBAL, Felippe. "Quadro Negro: Justiça seqüestra apartamento de ex diretor de Richa". 29 de setembro de 2017. Disponível em < http://www.gazetadopovo.com.br/politica/parana/quadronegro-justica-sequestra-apartamento-de-ex-diretor-de-richa-az7amqxm5j3gkkuvr8ko49ua1> Acesso em: 01/11/2017.

ANNIBAL, Felippe; RIBEIRO, Diego. "Um ano depois da batalha do Centro Cívico". Disponível em < http://www.gazetadopovo.com.br/vida-publica/especiais/batalha-do-centro-civico/index.jpp> Acesso em: 25/11/2017.

AYER, Flávia. "Corrupção está enraizada no Brasil desde o período colonial”. 13 de agosto de 2017. Disponível em < https://www.em.com.br/app/noticia/politica/2017/08/13/interna_politica,891482/corrupcaoesta-enraizada-no-brasil-desde-o-periodo-colonial-revela-hi.shtml> Acesso em: 25/11/2017

BAND NEWS: "Suspeito de fraude em licitações do governo do Estado é solto em Londrina". 24 de março de 2015. Disponível em < http://bandnewsfmcuritiba.com/suspeito-de-fraude-emlicitacoes-do-governo-do-estado-e-solto-em-londrina/ > Acesso em 22/11/2017.

BONDE NEWS: "Confira a lista dos 125 denunciados no esquema da Receita Estadual". 30 de junho de 2015. Disponível em < http://www.bonde.com.br/bondenews/politica/confira-a-lista-dos-125denunciados-no-esquema-da-receita-estadual-375644.html> Acesso em: 03/11/2017.

DESENVOLVIMENTO SOCIAL: "Quem é a Secretária." Disponível em <http://www.desenvolvimentosocial.pr.gov.br/pagina-1249.html> Acesso em: 20/12/2017.

GAECO: Grupo de atuação especial de combate ao crime organizado. Disponível em <http://www.gaeco.mppr.mp.br/> Acesso em: 01/11/2017.

GAZETA: Acompanhe a trajetória política de Beto Richa. 05 de outubro de 2014. Disponível em < http://www.gazetadopovo.com.br/vida-publica/eleicoes/2014/acompanhe-a-trajetoria-politicade-beto-richa-eejb4zj5xl9iyurpxcqlbb68e> Acesso em: 22/11/2017.

JUSTI, Adriana; RIBEIRO, Diego; VIANNA, José. "Ex diretor da Secretaria de Educação do Paraná é preso na 3a fase da Operação Quadro Negro". 16 de Setembro de 2017. Disponível em < 
https://g1.globo.com/pr/parana/noticia/ex-diretor-da-secretaria-de-eduacacao-do-parana-epreso-na-3-fase-da-operacao-quadro-negro.ghtml> Acesso em: 01/11/2017.

MARTINEZ, Jordana. "Luiz Abi Antoun é condenado a 13 anos por fraude em licitação". 29 de agosto de 2016. Disponível em < http://paranaportal.uol.com.br/cidades/luiz-abi-antoum-econdenado-a-13-anos-por-fraude-em-licitacao> Acesso em: 16/11/2017

MINISTÉRIO: GAECO - Operação Quadro Negro combate fraudes em licitações na área da educação. 11 de janeiro de 2013. Disponível em <http://www.mppr.mp.br/modules/noticias/article.php?storyid=3150> Acesso em: 03/11/2017.

MINISTÉRIO: O trabalho do Gaeco - Leonir Batisti. 08 agosto de 2017. Dispoível em <http://www.mppr.mp.br/modules/conteudo/conteudo.php?conteudo=7198>. Acesso em: $31 / 10 / 2017$.

MINISTÉRIO: Operação Publicano - Gaeco cumpre mandados de busca em Londrina, Campo Mourão e Mauá da Serra. 19 de outubro de 2017. Disponível em <http://www.mppr.mp.br/modules/noticias/article.php?storyid=7935> Acesso em: 03/11/2017.

MINISTÉRIO: Operação Quadro Negro - Gaeco denuncia a justiça 15 pessoas por desvio de dinheiro em obras de escolas. 07 de janeiro de 2016. Disponível em <http://www.mppr.mp.br/modules/noticias/article.php?storyid=6058> Acesso em: 03/11/2017.

MINISTÉRIO: Quadro Negro - Gaeco Curitiba cumpre mandato de prisão contra ex diretor da Secretaria de educação do estado. 16 de Setembro de 2017. Disponível em < http://www.mppr.mp.br/modules/noticias/article.php?storyid=7832> Acesso em: 01/11/2017.

MOSER, Sandro. "Nepotismo legal persiste na gestão de Richa". 08 de dezembro de 2010. Disponível em <http://www.gazetadopovo.com.br/vida-publica/nepotismo-legal-persiste-nagestao-de-beto-richa-0xw2k777byy4mssr3yx4ihkcu> Acesso em: 20/12/2017.

OLIVEIRA, Cida. "Beto Richa não dialoga e estudantes já ocupam 600 escolas no Paraná". 17 de outubro de 2016. Disponível em <https://www.ocafezinho.com/2016/10/18/conhecido-comoditador-do-parana-beto-richa-nao-dialoga-com-estudantes-que-ja-ocupam-600-escolas/> Acesso em: 23/11/2017.

OSTI, Cláudio. "Publicano: Conselho nacional cobra explicações de promotores de Londrina". 24 de agosto de 2017. Disponível em < http://www.fabiocampana.com.br/2017/08/publicano-conselhonacional-cobra-explicacoes-de-promotores-de-londrina/> Acesso em: 16/11/2017.

OYA, Cristiane; CORDEIRO, Luciane. "Delator da Operação Publicano é exonerado do cargo de auditor fiscal". 16 de novembro de 2016. Disponível em < http:/g1.globo.com/pr/parana/operacao-publicano/noticia/2016/11/delator-da-operacaopublicano-e-exonerado-do-cargo-de-auditor-fiscal.html> Acesso em: 22/11/2017.

REIS, Lucas. "Esquema na receita do Paraná funcionava havia três décadas, diz Procuradoria". 16 de junho de 2015. Disponível em < http://www1.folha.uol.com.br/poder/2015/06/1642723- 
esquema-na-receita-no-pr-funcionava-ha-tres-decadas-diz-ministerio-publico.shtml> Acesso em: 15/11/2017.

RIBEIRO, Diego; GIMENES, Erick. "Justiça inocenta Beto Richa , Francischini e outros 4 por ação policial do 29 de abril". 15 de agosto de 2017. Disponível em < https://g1.globo.com/pr/parana/noticia/justica-inocenta-beto-richa-francischini-e-outros-4-poracao-policial-do-29-de-abril.ghtml> Acesso em: 25/11/2017.

RUSCHEL, René. "O primo complica Beto Richa". 12 de abril de 2015. Disponível em < https://www.cartacapital.com.br/revista/844/o-governador-e-o-primo-1737.html> Acesso em: 22/11/2017.

SAMPAIO, Herval; MORAIS, Joyce; GUIZZO, Affonso. "O DNA da corrupção, infelizmente, está em um cada um de nós!" 2016. Disponível em < https://joseherval.jusbrasil.com.br/artigos/395382542/o-dna-da-corrupcao-infelizmente-esta-emum-cada-um-de-nos> Acesso em: 26/11/2017.

SANTOS, Ivan. "Gaeco cumpre mandatos no interior em nova fase da operação Publicano". 19 de outubro de 2017. Disponível em <http://www.bemparana.com.br/politicaemdebate/index.php/tag/operacao-publicano/> Acesso em: 03/11/2017.

SAVIANI, Rodrigo. "Nome de Beto Richa aparece em investigações do Ministério Público". 26 de maio de 2015. Disponível em < http://g1.globo.com/pr/parana/noticia/2015/05/nome-de-betoricha-aparece-em-investigacoes-do-ministerio-publico.html> Acesso em: 15/11/2017.

SCORTECCI, Catarina. "Ex diretor da Seed e donos de construtora são presos". 21 de julho de 2015. Disponível em < http://www.gazetadopovo.com.br/vida-e-cidadania/ex-diretor-da-seed-e-donosde-construtora-sao-presos-1iuuoeu2n9qbew2x8bpzmpykz> Acesso em: 01/11/2017.

SCORTECCI, Catarina. "Fator Richa: Ações da Quadro Negro e da Publicano agora dependem de Brasília." 10 de outubro de 2017. Disponível em <http://www.gazetadopovo.com.br/politica/parana/fator-richaacoes-da-quadro-negro-e-dapublicano-agora-dependem-de-brasilia-37tdzx9y51byjkk95ft6yksq9> Acesso em: 15/11/2017.

SCORTECCI, Catarina. "Por envolverem Beto Richa, processos da Publicano terão de ser enviados ao STJ". 20 de agosto de 2017. Disponível em <http://www.gazetadopovo.com.br/politica/parana/por-envolverem-richa-processos-dapublicano-terao-de-ser-enviados-ao-stj-c612kpzjkcv219086ohn3qbwo> Acesso em 16/11/2017.

SCORTECCI, Catarina. "Quem é Maurício Fanini, o suposto longa manus do governador Beto Richa?". 11 de outubro de 2017. Disponível em

<http://www.gazetadopovo.com.br/politica/parana/quem-e-mauricio-fanini-o-supostolonga-manus-do-governador-beto-richa-9sbycdmoote6cdcnllyz50vo7> Acesso em: 01/11/2017. 
TRIBUNA: Trajetória política de Beto Richa começa em 1994. 06 de outubro de 2008. Disponível em < http://www.tribunapr.com.br/noticias/politica/trajetoria-politica-de-beto-richa-comeca-em1994/> Acesso em: 21/11/2017.

WILLE, José. "A carreira política do ex governador José Richa". 28 de agosto de 2016. Disponível em <http://paranaportal.uol.com.br/blogs-memoria-paranaense/a-carreira-politica-do-exgovernador-jose-richa/> Acesso em: 21/11/2017.

\section{REFERÊNCIAS CONSULTADAS}

ALESSI, Gil. "Entenda o que é a PEC 214 e como ela pode afetar sua vida". 13 de dezembro de 2016. Disponível em

<https://brasil.elpais.com/brasil/2016/10/10/politica/1476125574_221053.html> Acesso em: 25/11/2017.

ROCHA, Marcelo. "Como se desvia dinheiro no Brasil". 27 de janeiro de 2012. Disponível em < http://revistaepoca.globo.com/ideias/noticia/2012/01/como-se-desvia-dinheiro-no-brasil.html> Acesso em: 24/11/2017.

OLIVEIRA, Ricardo Costa de. O Silêncio dos Vencedores: genealogia, classe dominante e Estado do Paraná. Curitiba: Moinho do Verbo, 2001. 447p. 